\title{
Assessment the Domestic Violence among Infertile Women at Benha University Hospital
}

\section{Maha Ghazy Diab ${ }^{1}$, Samia Abd El hakeem Hasneen ${ }^{2}$, Somaya Ouda AbdEImoniem ${ }^{3}$ and Ola Abdel Wahab Afify ${ }^{4}$}

(1) Nurse Specialist in Al-Shouhada Central Hospital, (2) Professor of Maternity and Gynecological Nursing, Faculty of Nursing, Benha University (3) Assistant professor of Obstetric and Woman's Health Nursing, Faculty of Nursing, Benha University and (4) Lecturer of Obstetric and Woman's Health Nursing, Faculty of Nursing, Benha University

\begin{abstract}
Background: Infertility is defined as failure of conception for one year or more in spite of regular unprotected appropriately timed intercourse. Violence affects the lives of millions of infertile women worldwide, regardless of their socioeconomic and educational level. The aim of the study: Was to assess the domestic violence among infertile women at Benha University Hospital. Design: Descriptive study design. Setting: The study was conducted at Benha university hospital among infertile women attended to obstetrics and gynecology outpatient clinics. Sample: Purposive sample was used to conduct the study. Tools of data collection: Were consisted of 2 tools, I. Self-administrated questionnaire that includes socio-demographic characteristics, couple's health status and infertility profile. II: Domestic violence against infertile women structured interview schedule it was consists of two main parts includes pattern of violence and violence correlates. Results: There was a highly statistically significant relation between physical violence, sexual violence and (residence and type of family). Additionally, there was a highly statistically significant relation between Psychological violence and (level of education). Additionally, there was statistically significant relation between psychological violence and (age of spouses). Conclusion: Infertile women were exposed to different patterns of intimate partner violence. Slightly more than half of the studied women, more than half and the majority of them suffered from physical, sexual and psychological violence respectively. Recommendations: Routine screening for domestic violence in infertility clinics should be mandatory to identify the victims, and provide them with appropriate health care and supportive services.
\end{abstract}

Key words: Infertility, primary infertility, secondary infertility and domestic violence

\section{Introduction}

Infertility is defined as failure of conception for one year or more in spite of regular unprotected appropriately timed Intercourse. The failure of married couples to achieve pregnancy despite the couple desire to do so means inability to fully realize the couple aim to have a family. Having children especially in our society in general is essential goal of marriage and a social responsibility for a family (Rahnavardi et al, 2019).
Regarding incidence of infertility globally, $10-15 \%$ of the couples are infertile and secondary infertility out numbers the primary. Infertility is important not only in context of its physical entity but as a social milieu too. Infertility can have serious implications on psychological, physical, economic and social well-being for both spouses, but more for women as motherhood is seen as a supreme achievement for a woman and demonstrates women physical 
and psychological adequacy (Andreeva, 2018).

Domestic Violence (DV) is defined as exerting any violent behavior against another person and within an intimate relationship, and includes physical, psychological and sexual violence. Violence affects the lives of millions of infertile women worldwide, regardless of their socioeconomic and educational level (Ameh, 2019).

Studies have reported that in the presence of infertility, the prevalence of violence toward women from woman's husbands or partners ranged between $1.8 \%$ and $77.8 \%$ in the world. Psychological violence was the most frequently seen type of violence in infertile women. Because of the cultural perception that infertility is the problem of women alone, violence against women is more common in the maledominated social structure (Xiaoli et al, 2016).

Consequently, women dealing with DV or its aftermath are more likely than women with no history of abuse to use health services including emergency departments, outpatient clinics, and in-patient units. Each of these visits affords an opportunity for healthcare professionals to address women's experiences of DV and minimize negative health consequences. As the largest healthcare workforce globally, nurses are more likely to interact with women experiencing DV than any other healthcare professionals ( Namdar et al, 2017).

\section{Significance of the study}

Domestic violence is a global disaster. Usually, women are the prime victims of domestic violence. Infertility may affect the public health in many countries. Domestic violence is the intentional use of physical force, power or threat against oneself, another person or another group or community which leads to injury, death, mental harm, and lack of development or deprivation (Al-Turki, 2015).

It is becoming more and more evident that infertility and gender based violence are the emerging health problems especially developing countries as Egypt (WHO, 2017). Generally speaking violence against women is a major health and human right concern. The prevalence of violence ranges between $15 \%-71 \%$ worldwide. Global estimates published by WHO indicated that about one in three $(35 \%)$ women worldwide had experienced either physical and/or sexual violence in their lifetime. On the other hand, Egypt Demographic and Health Survey (EDHS) 2018 estimated that one in four women aged 15-49 years reported physical violence by their husbands (EDHS, 2018). In Egypt there are limited study about the relationship between domestic violence and infertility, the present study was conducted with the aim of aspsessment the domestic violence among infertile women at Benha university hospital (Omani et al, 2018).

\section{Aim of the study:}

The aim of the present study was to assess the domestic violence among infertile Women at Benha University Hospital.

\section{Research question:}

- What are patterns of domestic violence?

- What is the violence correlates?

\section{Subjects and Method:}

Study design:

A descriptive research design was used to fulfill the aim of this study.

\section{Study setting:}

This study was conducted at obstetrics and gynecology outpatient clinics, Benha university hospital, Qalioubia Governorate. 


\section{Sampling:}

Sample size: included 85 infertile women attended to previous setting for six months.

Sample type: A purposive sample was selected from the above mentioned study setting according to the following inclusion criteria:

- Women at reproductive age $(18-45)$ years old.

- Married for at least one year without any contraceptives.

- Willing to participate in the study.

- At least read and write.

- Regular sexual relationship.

Tools used for data collection: two tools were structured to collect necessary data.

Tool I: Self-administered questionnaire ،

It was developed by the researcher based on recent relevant literature. It was include four parts as following:

\section{Part (1): Socio-demographic} characteristics such as (age, age at marriage, duration of marriage, body mass index (BMI), religion, residence, level of education, women's occupation, income, family type and husband's occupation, age, level of education).

\section{Part (2): Couple's Health status:}

- Past medical history: for women as (presence of medical diseases, types of medical diseases and taking medication or drugs regularly). Women's husband as (presence of medical diseases, types of medical diseases, taking medication or drugs regularly and taking sedatives, conditioners, or medication when bothered).

- History for women, gynecological surgery such as (laparoscopy, hysteroscopy, surgical removal of ovarian cyst or curettage).
- Gynecological history such as (menstrual irregularities, endometritis, vaginitis, cervicitis, salpingitis, polycystic ovary syndrome, fallopian tube obstruction, sub-mucous fibroid or adhesions).

Part (3): Infertility profile such as (type of infertility, duration of infertility, cause of infertility, seeking medical care, performing investigation, type of investigations, medication in take to treat infertility, duration of treatment, used traditional practices, in-vitro fertilization (IVF) attempts and performing frequency of in vitro fertilization (IVF) attempts, traditional practices such as (consulting traditional healers, visiting graveyards, visiting religious leaders, using traditional alternative therapy as herbs, hijama, taking bath by necklac and crossing over placenta of delivered woman) and female causes of infertility such as (menstrual irregularities, polycystic ovary syndrome (POS), fallopian tube obstruction, salpingitis, endometriosis, sub-mucous fibroid, adhesion or unexplained infertility).

Tool II: Domestic violence against infertile women structured interview schedule it was consisted of two main parts:

\section{Part (1): Pattern of violence:}

This tool was developed by (Ghaly et al., 2019) to determine the pattern of violence against infertile women. It was adapted and translated into Arabic language by the researcher. It was consist of three sections:

\section{Section 1: Physical violence}

Forms of physical violence such as (kicking, slapping, twisting arm, pushing, kicking, throwing with objects and others (threating with killing), beating in the presence of others such as (husband's family, women's family, neighbors, friends or in the street), presence of injuries, seeking medical 
care from doctor or hospital, mother-in-law to punish you with difficult housework and forcing you to do some traditional practices that is believed to facilitate pregnancy.

\section{Section 2: Psychological violence}

Forms of psychological violence such as (quarrel, mockery, throw her out of home women, contempt, compare negatively with other fertile, isolation and imprisonment), partner threatens with divorce or getting married to a fertile women, public humiliation in front of everyone, mother-in-law uses of grieving names as infertile or unproductive nicknames infertile or un productive, resort to isolation and not to leave the house, husband is the cause of infertility, pushing you to declare that you are the cause, ignoring your decisions and exposure to strange questions such as "why aren't you pregnant yet, have you had IVF" or ignoring women's decisions).

\section{Section 3: Sexual violence}

Forms of sexual violence such as (husband has the right to have sex at any time even if her don't want, husband forcibly forced you to have sexual intercourse, humiliation during sexual intercourse, satisfying you desire for sexual intercourse, husband abstained from having sexual intercourse with you and husband forced you to have illegal sexual intercourse).

\section{Part (2): Violence correlates:}

It contains three main parts:

A. Reasons for domestic violence such as (family pressure, continuous visits unaccessibility to infertility clinics, difficulty to follow sexual intercourse timetable as physician order, repeated or failed IVF, high cost of treatment, or having problems with husband's family).

B. Violence aggressors such as (husband, husband's family, wife's family, friends or neighbors).

C. Women's response to violence such as (no reaction, leaving home, isolation and not leaving the house, crying and shouting, refrain from going to the doctor and discontinuation of treatment, speak together to find solution or requesting divorce). Seek to help when exposed to violence, women requesting help from (wife's family, friends or neighbors, the doctor or health workers or husband's family). Women not request helping because ( afraid of hitting, afraid of getting divorce, afraid of not giving money for treatment, afraid of getting married to a fertile woman, afraid of problems with husband's family or it is considered individual matter cannot be mentioned).

\section{Ethical consideration:}

Ethical aspect was considered before starting the study that included the following: - The research approval was obtained from Scientific Research Ethical Committee, Faculty of Nursing at Benha University before starting the study.

- An oral consent was obtained from each woman before starting data collection.

- The studied sample was informed about the purpose, benefits of the study and time throughout the study.

- The researcher emphasized that participation is voluntary.

-Each woman had the freedom to withdraw at any time of participation without obligation.

-The study didn't harm dignity, tradition and religious aspects of the women.

-Confidentiality and privacy were ensured throughout the study process and the students were assured that all data was used only for research purpose.

\section{Validity and reliability of the tools:}

Tools were developed by the researcher after the review of literature. The tool was tested for its content validity by panels of three experts in the field of obstetrics (two maternity nursing professors and one obstetrician) at Faculty of Benha University 
to test content validity. Their opinions were elicited regarding the tools format layout, consistency and scoring system. The experts reviewed the tools for clarity of sentences, consistency, and appropriateness of content, the sequence of items, accuracy, relevance, comprehensiveness, simplicity and applicability of tools. The reliability was done by Cranach's Alpha coefficient test which revealed that each of the tools consisted of relatively homogenous items as indicated by the moderate to high reliability of each tool was (0.86).

Pilot study:

A pilot study was conducted on $10 \%$ of the total sample size ( 8 infertile women) before starting data collection to test the clarity, arrangement of the items, feasibility and applicability of the tools as well as to estimate the needed time to fill questions and to make sure that items are understood. Also to find out the possible obstacles and problems that might face the researchers and interfere with data collection. According to the results of pilot study required modifications were done. The women involved in the pilot sample were being excluded from the study.

\section{Field work:}

- Data were collected through a period of six months from the beginning of June 2020 to the end of November 2020 in obstetrics and gynecology outpatient clinics at Benha university hospitals.

- The researcher visited the previously mentioned sittings, two days (Saturdays and Wednesdays) weekly from 9 a.m. to 12 p.m. The researcher introduced herself, greet women, the purpose of the study was explained by the researcher and oral consent was taken to participate in this study. The average number of women that the researcher met was about 1-2 women /day. The researcher met the women at waiting room of outpatient clinics at Benha university hospitals.

- The researcher interviewed the infertile women and distributed (Tool I) which was self - administrated questionnaire (socio-demographic characteristics, couple's health status and infertility profile) to be fulfilled by them.

- The time needed to complete the selfadministered questionnaire was ranged from 25- 35 minutes.

- Then the studied infertile women were given (Tool II) which was domestic violence against infertile women structured interview schedule (pattern of violence and violence correlates). The required time to complete this part was approximately 15-20 minutes.

\section{Statistical analysis:}

Data was verified prior to computerized entry. The statistical package for social science (SPSS version 20) was used for that purpose, followed by data tabulation and analysis. Descriptive statistics were applied (e.g., mean, standard, deviation, frequency and percentage). Test of significance (t-test, chi-squre). A significant level value was considered when $\mathrm{p}-<0.05$.In addition, a highly significant level value was considered when $\mathrm{p}<0.01$.

\section{Results}

Table (1) shows that, the general characteristics data of the studied women, it was cleared that more than thirty $(41.2 \%)$ of the studied sample was in the age group of 30- 39 years with a mean age of $31.12 \pm 7.60$ years. Considering age at marriage, more than half $(58.8 \%)$ of them married at the age of 20 24 years with mean age of women at marriage was $23.11 \pm 3.49$. Regarding the duration of marriage, more than half $(58.8 \%)$ of them are married for more than 5 years. Also, more 
than two-thirds (62.4\%) of women lived in rural areas. Regarding educational level, more than one thirty of them (43.5\%) had secondary education. In addition; regarding occupation, more than three-quarters $(76.5 \%)$ of them were housewife. Moreover; the income of more than half of them $(58.8 \%)$ was fairly enough. Finally, the majority of them were Muslim (94.1\%).

Figure (1) illustrates that, slightly more than half of the studied women $(51.8 \%)$ suffered from Physical violence, more than half $(57.6 \%)$ suffered from sexual violence and the majority $(81.2 \%)$ of them suffered from psychological violence.

Table (2) reveals that the majority of studied women had primary infertility (87.1). More than half $(56.5 \%)$ of them were infertile for 4 years or more. Concerning causes of infertility more than half $(52.9 \%)$ of them had female factor of infertility. It was clear that all $(100 \%)$ women were seeking medical care and performing investigations. In relation to administration of medication, less than twothirds $(61.2 \%)$ of them were taking medications to treat infertility. Meanwhile the duration of treatment of infertility was slightly less than half of them $(49.4 \%)$ were less than 5 years. About one-third of them $(30.6 \%)$ reported doing IVF and $(84.6 \%)$ of them did it for once. Increasingly slightly more than two-third of them $(65.9 \%)$ of them reported practicing traditional practices such as: herbs $(53.6 \%)$, but visiting graveyards $(32.1 \%)$ and visiting religious leaders (44.6\%).

Table (3) clarifies that, there was a highly statistically significant relation between physical violence, sexual violence and (residence and type of family) ( $\mathrm{p} \leq 0.001 \&$ ( $\mathrm{p}$ $\leq 0.05$ ). Additionally, there was a highly statistically significant relation between Psychological violence and (level of education).

Table (4) illustrates that, there was a highly statistically significant positive correlation between total psychological violence scores and total physical violence scores. Moreover, there was a highly statistically significant positive correlation between total psychological violence scores and total sexual violence scores. 
Table (1): Frequency distribution regarding general characteristics of the studied sample $(\mathbf{N}=85)$.

\begin{tabular}{|c|c|c|}
\hline General characteristics & No & $\%$ \\
\hline \multicolumn{3}{|l|}{ Age in (years) } \\
\hline$<20$ & 5 & 5.9 \\
\hline $20-<30$ & 30 & 35.3 \\
\hline $30-<40$ & 35 & 41.2 \\
\hline$\geq 40$ & 15 & 17.6 \\
\hline \multicolumn{3}{|c|}{ Mean \pm SD $=31.12 \pm 7.60$} \\
\hline \multicolumn{3}{|l|}{ Age at marriage in (years) } \\
\hline$<20$ & 10 & 11.8 \\
\hline $20-<25$ & 50 & 58.8 \\
\hline $25-<30$ & 20 & 23.5 \\
\hline$\geq 30$ & 5 & 5.9 \\
\hline \multicolumn{3}{|c|}{ Mean \pm SD $=23.11 \pm 3.49$} \\
\hline \multicolumn{3}{|l|}{ Duration of marriage in (years) } \\
\hline$<5$ & 25 & 29.4 \\
\hline 5 & 10 & 11.8 \\
\hline$>5$ & 50 & 58.8 \\
\hline \multicolumn{3}{|l|}{ Religion } \\
\hline Muslim & 80 & 94.1 \\
\hline Christian & 5 & 5.9 \\
\hline \multicolumn{3}{|l|}{ Residence: } \\
\hline Rural & 53 & 62.4 \\
\hline Urban & 32 & 37.6 \\
\hline \multicolumn{3}{|l|}{ Level of Education } \\
\hline Read \& write & 10 & 11.8 \\
\hline Basic education & 18 & 21.2 \\
\hline Secondary education & 37 & 43.5 \\
\hline University education & 20 & 23.5 \\
\hline \multicolumn{3}{|l|}{ Occupation } \\
\hline Housewife & 65 & 76.5 \\
\hline Employer & 20 & 23.5 \\
\hline \multicolumn{3}{|l|}{ Income } \\
\hline Enough & 10 & 11.8 \\
\hline Fairly enough & 50 & 58.8 \\
\hline Not enough & 25 & 29.4 \\
\hline \multicolumn{3}{|l|}{ Family type } \\
\hline Nuclear & 56 & 65.9 \\
\hline Extended & 29 & 34.1 \\
\hline
\end{tabular}

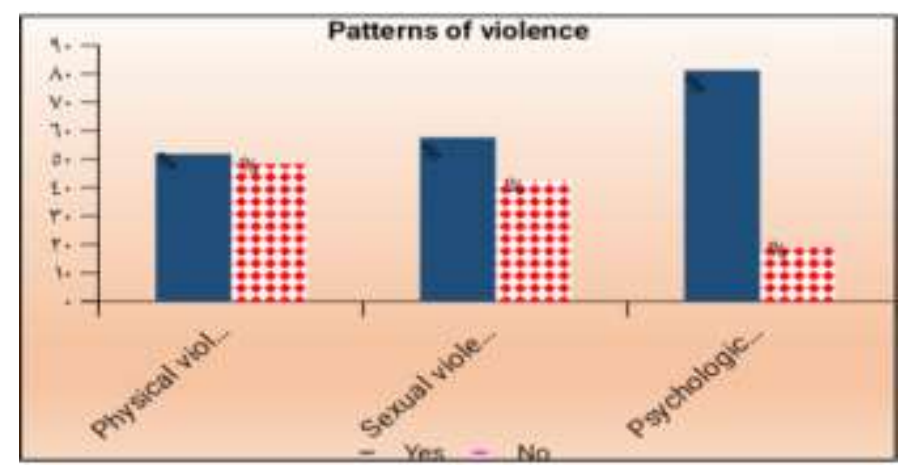

Figure (1): Frequency distribution of the studied sample's spouses according to their patterns of violence $(\mathbf{N}=\mathbf{8 5})$. 
Table (2): Frequency distribution of the studied sample according to their infertility profile (N = 85).

\begin{tabular}{|c|c|c|}
\hline Items of couples' infertility profile & $\overline{\text { No }}$ & $\%$ \\
\hline \multicolumn{3}{|l|}{ Type of infertility } \\
\hline Primary & 74 & 87.1 \\
\hline Secondary & 11 & 12.9 \\
\hline \multicolumn{3}{|l|}{ Duration of infertility in years } \\
\hline 1 year & 5 & 5.9 \\
\hline 2 years & 12 & 14.1 \\
\hline 3 years & 20 & 23.5 \\
\hline$\geq 4$ years & 48 & 56.5 \\
\hline \multicolumn{3}{|l|}{ Causes of infertility } \\
\hline Female cause & 59 & 69.5 \\
\hline Unexplained infertility & 26 & 30.5 \\
\hline \multicolumn{3}{|l|}{ Seeking medical care } \\
\hline Yes & 85 & 100.0 \\
\hline No & 0 & 0.0 \\
\hline \multicolumn{3}{|l|}{ Performing investigations } \\
\hline Yes & 85 & 100.0 \\
\hline No & 0 & 0.0 \\
\hline \multicolumn{3}{|l|}{ If yes, type of Investigations* } \\
\hline Ovulation detection by U/S & 85 & 100.0 \\
\hline Hormonal assay & 85 & 100.0 \\
\hline Hestrosalpingography (HCG) & 23 & 27.1 \\
\hline Endometrial biopsy & 3 & 3.5 \\
\hline Laparoscopy & 24 & 28.2 \\
\hline Hysteroscopy & 6 & 7.1 \\
\hline \multicolumn{3}{|l|}{ Medication intake to treat infertility } \\
\hline Yes & 52 & 61.2 \\
\hline No & 33 & 38.9 \\
\hline \multicolumn{3}{|l|}{ Duration of infertility treatment in years } \\
\hline$<5$ & 42 & 49.4 \\
\hline 5 & 9 & 10.6 \\
\hline$>5$ & 34 & 40 \\
\hline \multicolumn{3}{|l|}{ In-vitro fertilization (IVF) attempts } \\
\hline Yes & 26 & 30.6 \\
\hline No & 59 & 69.4 \\
\hline \multicolumn{3}{|l|}{ Frequency of IVF attempts $(n=26)$} \\
\hline Once & 22 & 84.6 \\
\hline Twice & 3 & 11.5 \\
\hline$>$ Twice & 1 & 3.9 \\
\hline \multicolumn{3}{|l|}{ Traditional practices } \\
\hline Yes & 56 & 65.9 \\
\hline No & 29 & 34.1 \\
\hline \multicolumn{3}{|l|}{ Type of traditional practices $(n=56) *$} \\
\hline Herbs & 30 & 53.6 \\
\hline Visiting graveyards & 18 & 32.1 \\
\hline \begin{tabular}{|l|} 
Visiting religious leaders \\
\end{tabular} & 25 & 44.6 \\
\hline \begin{tabular}{|l|} 
Traditional healers \\
\end{tabular} & 14 & 25.0 \\
\hline Hijama & 6 & 10.7 \\
\hline Taking bath by necklace & 8 & 14.3 \\
\hline Crossing over placenta of delivered woman & 4 & 7.1 \\
\hline
\end{tabular}


Maha Ghazy, Samia Abd El hakeem, Somaya Ouda and Ola Abdel Wahab

Table (3): Relation between general characteristics of the studied sample and patterns of violence

\begin{tabular}{|c|c|c|c|c|c|c|}
\hline \multirow{4}{*}{ general characteristics } & \multicolumn{6}{|c|}{ Patterns of violence } \\
\hline & \multirow{2}{*}{\multicolumn{2}{|c|}{$\begin{array}{c}\begin{array}{c}\text { Physical } \\
\text { violence }\end{array} \\
\text { Yes } \\
(n=44)\end{array}$}} & \multirow{2}{*}{\multicolumn{2}{|c|}{$\begin{array}{c}\begin{array}{c}\text { Sexual } \\
\text { violence }\end{array} \\
\text { Yes } \\
(\mathbf{n}=49)\end{array}$}} & \multicolumn{2}{|c|}{$\begin{array}{c}\text { Psychological } \\
\text { violence }\end{array}$} \\
\hline & & & & & & $\begin{array}{l}\text { es } \\
69)\end{array}$ \\
\hline & No & $\%$ & No & $\%$ & No & $\%$ \\
\hline \multicolumn{7}{|c|}{ Age } \\
\hline$<20$ & 2 & 4.5 & 2 & 4.1 & 4 & 5.8 \\
\hline $20-<30$ & 15 & 34.1 & 15 & 30.6 & 27 & 39.1 \\
\hline $30-<40$ & 18 & 40.9 & 26 & 53.1 & 28 & 40.6 \\
\hline$\geq 40$ & 9 & 20.5 & 6 & 12.2 & 10 & 14.5 \\
\hline$\chi 2(p-v a l u e)$ & \multicolumn{2}{|c|}{$.724(.868)$} & \multicolumn{2}{|c|}{$7.238(.065)$} & \multicolumn{2}{|c|}{$3.631(.304)$} \\
\hline \multicolumn{7}{|c|}{ Residence } \\
\hline Rural & 41 & 93.2 & 39 & 79.6 & 42 & 60.9 \\
\hline Urban & 3 & 6.8 & 10 & 20.4 & 27 & 39.1 \\
\hline$\chi 2(p-v a l u e)$ & \multicolumn{2}{|c|}{$36.933\left(.000^{* *}\right)$} & \multicolumn{2}{|c|}{$14.647(.000 * *)$} & \multicolumn{2}{|c|}{$.344(.558)$} \\
\hline \multicolumn{7}{|c|}{ Educational level: } \\
\hline Read \& write & 5 & 11.4 & 5 & 10.2 & 9 & 13.0 \\
\hline Basic education & 9 & 20.5 & 12 & 24.5 & 16 & 23.2 \\
\hline Secondary education & 18 & 40.9 & 22 & 44.9 & 34 & 49.3 \\
\hline University education & 12 & 27.3 & 10 & 20.4 & 10 & 14.5 \\
\hline$\chi 2(p-v a l u e)$ & \multicolumn{2}{|c|}{$.722(.868)$} & \multicolumn{2}{|c|}{$1.368(.713)$} & \multicolumn{2}{|c|}{$16.712(.001 * *$} \\
\hline \multicolumn{7}{|c|}{ Occupation } \\
\hline House wife & 32 & 72.7 & 39 & 79.6 & 55 & 79.7 \\
\hline Employer & 12 & 27.3 & $\mathbf{1 0}$ & 20.4 & 14 & 20.3 \\
\hline$\chi 2(p-v a l u e)$ & \multicolumn{2}{|c|}{$.710(.339)$} & \multicolumn{2}{|c|}{$.626(.429)$} & \multicolumn{2}{|c|}{$2.138(.144)$} \\
\hline \multicolumn{7}{|c|}{ Income } \\
\hline Enough & 5 & 11.4 & 5 & 10.2 & 10 & 14.5 \\
\hline Fairly enough & 26 & 59.1 & 29 & 59.2 & 35 & 50.7 \\
\hline No enough & 13 & 29.5 & 15 & 30.6 & 24 & 34.8 \\
\hline$\chi 2(p$-value $)$ & \multicolumn{2}{|c|}{$.014(.993)$} & \multicolumn{2}{|c|}{$.299(.861)$} & \multicolumn{2}{|c|}{$10.001(.007)$} \\
\hline \multicolumn{7}{|c|}{ Type of family } \\
\hline Nuclear & 16 & 36.4 & 26 & 53.1 & 46 & 66.7 \\
\hline Extended & 28 & 63.6 & 23 & 46.9 & 23 & 33.3 \\
\hline$\chi 2(p-v a l u e)$ & \multicolumn{2}{|c|}{$35.362(.000 * *)$} & \multicolumn{2}{|c|}{$8.461(.004 *)$} & \multicolumn{2}{|c|}{$.100(751)$} \\
\hline
\end{tabular}

*A Statistically significant $\mathrm{p} \leq 0.05 * *$ A Highly Statistical significant $\mathrm{p} \leq 0.001$. 
Assessment the Domestic Violence among Infertile Women at Benha University Hospital

Table (4): Correlation coefficient between studied sample's psychological

\begin{tabular}{||c|c|c|c|}
\hline \multicolumn{2}{|c|}{ Topic } & Physical violence & Sexual violence \\
\hline \multirow{2}{*}{ Psychological violence } & $\mathrm{r}$ & .449 & .562 \\
\cline { 2 - 5 } & P value & $.000^{* *}$ & $.000^{* *}$ \\
\hline
\end{tabular}

\section{Discussion}

Infertility is a stressful condition as infertile women suffer from anxiety and depression because of not having a child as well as due to the fear of losing husband's interest. The situation becomes gloomier for those women who become the victims of violence due to their infertility. Moreover, the infertile women are not only socially stigmatized but also they have to bear the burden of being infertile and becoming the victims of violence. Domestic violence is one of the main social-public health and human rights issues that influence women's health (Tahiri et al, 2015).

General characteristics of the studied sample such as age, residence, occupation, educational level and income mainly affect domestic violence against infertile women. So these factors should be determined for the studied sample. The finding of the current study of the personal characteristics data of the studied women revealed that more than thirty of the studied sample was in the age group of 30- 39 years with a mean age of $31.12 \pm 7.60$ years. Considering age at marriage, more than half of them married at the age of 20- 24 years with mean age of women at marriage was 23.11 \pm 3.49 . Regarding the duration of marriage, more than half of them married for more than 5 years. Also, more than two-thirds of women lived in rural areas. Regarding educational level, more than one thirty of them had secondary education.
In addition; regarding occupation, more than three-quarters of them were housewife. Moreover; the income of more than half of them was fairly enough. Finally, the majority of them were Muslim.

This result was in accordance with, (Elkhateeb, 2018) who studied "Domestic violence against infertile women, in Egypt", reported that the women accepted participation in the study, mean age was $33.9 \pm 6.2$ years. Among women suffered from violence, $(75.7 \%)$ were housewives, (45\%) had secondary education and $(57.8 \%)$ medium socioeconomic standard. This similarity in results might be related to the similarities of community features and convergence in sample size.

In addition, the results of the present study came nearly in the same line with (Ghaly, et al, 2019) who studied "Intimate partner violence against infertile women, in Egypt", observed that less than one-half $(47.7 \%)$ of women aged 30 to less than 40 years; age at marriage, more than one-half (54\%) of women married at the age of 15 to less than 25 years, In relation to the duration of marriage, it was clear that more than five years among less than one-half $(45.7 \%)$ of women. Regarding occupation, it was illustrated that the majority $(82.3 \%)$ of women were housewives. Concerning women's residence, more than one-half $(54.7 \%)$ of women was living in rural areas. In relation to family type, it was found that more than two-thirds $(71 \%)$ of women had nuclear family. It was obvious that 


\section{Maha Ghazy, Samia Abd El hakeem, Somaya Ouda and Ola Abdel Wahab}

income was just enough for a living among about three-quarters $(74.3 \%)$ of women.

Moreover, the findings of current study came in accordance with, (Rahebi et al, 2019) who studied "Relationship between domestic violence and infertility ", found that nearly (55 $\%$ ) of participants in both fertile and infertile groups had average incomes. In this study the majority of women $(75 \%)$ were housewives. The education level of more than (45\%) of participants was secondary school in infertile group.

In addition, the results of the present study came nearly in the same line with, (Malgorzata et al, 2019) who studied "Gender Di_erences in the Experience of Infertility Concerning Polish Couples: Preliminary Research", cleared that the largest group (49 \%) among the respondents were people between 31 and 40 years of age. According to residence about (67.2\%) lived in rural area. This study agreed with, (Potura et al, 2019) who studied "An evaluation of the relationship between violence exposure status and personality characteristics among infertile women, Health Care for Women International", illustrated that the mean age of the participants was $32.41 \pm 4.18$ (min-max: 27-45), their mean marriage duration was $7.63 \pm 4.30$ (min-max: $3-25)$ years. It was found that $(27.6 \%)$ of the participants were elementary school graduates.

Concerning the infertility profile, the present study illustrate that the majority of studied sample suffered from primary infertility, more than half of them were infertile for 4 years or more. Concerning causes of infertility, more than half of them had female factor of infertility. It was clear that all women were seeking medical care and performing investigations. In relation to administration of medication, less than two-thirds of them were taking medications to treat infertility. Duration of infertility treatment of slightly less than half of them was less than 5 years. About one-third of them reported doing IVF and the majority of them did it for once. Increasingly, slightly more than twothird of them reported practicing traditional practices such as: herbs more than half of them, but visiting graveyards about one-third of them and visiting religious leaders less than half of them.

In this respect, the present findings were supported by, (Ghaly et al, 2019) proved that more than two-thirds of women were infertile for more than 3 years, concerning cause of infertility, it was obvious that more than onehalf of women had female factor infertility, while more than one-fifth of them had unexplained infertility. It was clear that all women were seeking medical care and doing investigations. In relation to medication intake, more than one-half of women were taking medications such as stimulants more than twothirds of them, medications for polycystic ovaries and regulation of menstruation $(21.7 \%$ and $4.2 \%$ ) respectively. The study also revealed that the duration of infertility treatment was more than 5 years in less than one-half of women, It was found that one-third of women underwent in-vitro fertilization, more than threequarters of them underwent in-vitro fertilization at least once. The study also illustrated that about one-quarter of women reported doing traditional practices such as: herbs (43.3\%), visiting graveyards $(39.5 \%)$, visiting religious leaders $(19.7 \%)$, and traditional healers (13.2 $\%)$. Also the results of this study came in the same line with, (Potura et al, 2019) who conducted "An evaluation of the relationship between violence exposure status and personality characteristics among infertile 


\section{Assessment the Domestic Violence among Infertile Women at Benha University Hospital}

women", illustrated that the majority $(80 \%)$ of the participants were found to have primary infertility, with $(52.1 \%)$ having female infertility, (20.9\%) having male infertility, (27 $\%)$ having unexplained infertility, and (10.8\%) having couple factor infertility.

Additionally, the findings of this study agreed with, (Budh et al, 2018) founded that the primary infertility among couples (85\%) was more than the secondary $(15 \%)$ infertility and it was mostly attributable to female factors (56.3 $\%)$ followed by male factors $(13.6 \%)$. In accordance with the previously mentioned findings were, (Otwori, 2017), who reported that female factor infertility constituted $(52.9 \%)$ of women.

On the other hand, the result of present study not the same line with the results of, (Taebi et al, 2016) who studied "Association between infertility factors and non-physical partner", concluded that the most common cause of infertility was male factor $(55 \%)$. On the other hand, the result of this study disagreed with, (Li et al, 2018) who studied "Depression in Chinese men undergoing different assisted reproductive technique treatment: Prevalence and risk factors", reported idiopathic factor (53.8 $\%)$ as the most common cause for infertility.

In addition, the result of our study disagreed with (Abd El Moneim, 2018) who conducted study in Kafer El- Dawar, Beheira Governorate, Egypt about "Traditional practices for treatment of infertility among rural women", reported that rituals were the most common used method such as taking bath by mushahara necklace, visiting mosques and licking certain stone beside the mosque until bleeding of the tongue occurs.

Violence affects women of all ages, races, and ethnic backgrounds, from all socioeconomic levels, all educational levels, and all walks of life. Violence is usually divided into three main categories: physical, psychological or emotional and sexual abuse. On assessing prevalence and patterns of violence in the present study, it was found that, the prevalence of physical, psychological and sexual violence was more than half, the majority and more than half, respectively. The commonest type of intimate partner violence experienced by women was the psychological violence. This could be attributed to more than one half of women were living in rural areas, where childbearing is considered a highly desirable aim and a source of power for women in the family and the society.

The results of this study came in the same line with, (Ghaly A et al, 2019) who illustrated that the majority $(96.3 \%)$ of women were exposed to psychological violence, one-half $(50.7 \%)$ of them were exposed to physical violence. And less than one-half $(45.7 \%)$ of them were exposed to sexual violence. Additionally, (Rahebi et al, 2019) who studied "Relationship between domestic violence and infertility", illustrate that $(58 \%)$ reported a history of physical violence, $(60 \%)$ had experienced sexual violence and $(77 \%)$ had psychological violence.

Furthermore, the previously mentioned results agreed with (Hasan et al, 2017) who studied " Prevalence and risk factor for domestic violence against infertile women in an Iranian setting", illustrate that The most common type of violence was psychological (83.8 \%), followed by physical (54\%) and sexual (55\%). The results of this study was in agreed with, (Sheikhan et al, 2019) who studied "Domestic violence in Iranian infertile women", found that the prevalence of physical violence was $(5.3 \%)$, 


\section{Maha Ghazy, Samia Abd El hakeem, Somaya Ouda and Ola Abdel Wahab}

psychological violence (74.3\%) and sexual violence $(47.3 \%)$ in infertile women.

In contrast to these results, (Potura et al, 2019) showed that $(22.5 \%)$ were exposed to physical violence and $(44.8 \%)$ were exposed to psychological. Moreover, the result of this study came in contrast with, (Ardabily et al, 2018) who studied "Prevalence and risk factors for domestic violence against infertile women in an Iranian setting", indicated that the prevalence of physical, psychological and sexual violence was (14\%), (33.8\%) and (8\%) respectively in infertile women, which was lower than the present study.

This discrepancy between the aforementioned study results and the finding of the current study may be attributed to the difference in cultural diversities in the study populations, as well as the different data collection tools.

Regarding to relation between sociodemographic characteristics of the studied women and pattern of violence the present study clarified that, there was a highly statistically significant relation between physical violence, sexual violence and (residence and type of family) $(\mathrm{p} \leq 0.001) \&$ $(\mathrm{p} \leq 0.05)$. Additionally, there was a highly statistically significant relation between psychological violence and (level of education). This results may came from most of participants lived in rural area in this area people have traditional ideas that might be aggressor to violence. Also most of them were in extended family that might be aggressor to violence due to family pressure to violence. This result related to that the woman that have high level of education affected more than the woman that have low level of education.

Additionally, this finding was in consistent with, (Sami and Ali, 2016) study, who reported that there was association between violence against infertile women and women's educational status. Such agreement between the current study finding and that of the three previously mentioned studies could be attributed to the fact that women with low educational level have to depend on their husband in cultures with male-centered domination

On the same line, this finding match with that of, (Mohamadian et al, 2016), who had done a study about "Prevalence and risk factors of domestic violence against Iranian women: A cross-sectional study", mentioned that there was no significant relationship between women's age and experience of domestic violence. Also, this finding disagrees with, (Keeling, 2015), who studied "Violence against women: current theory and practice in domestic abuse, sexual violence and exploitation", found a significant relationship between women's age and experiencing domestic violence.

Regarding correlation coefficient between studied sample's psychological, physical violence \& sexual violence the present study illustrated that, there was a highly statistically significant positive correlation between total psychological violence scores and total physical violence scores. Moreover, there was a highly statistically significant positive correlation between total psychological violence scores and total sexual violence scores.

\section{Conclusion}

The infertile women were exposed to different patterns of intimate partner violence. Slightly more than half of the studied women, more than half and the majority of them suffered from physical, sexual and psychological 
violence respectively. Less than two-thirds of them reported exposure to violence due to family pressure. More than two-thirds of women had experienced violence from husband's family. More than half of women responded to violence by isolation and not leaving the house.

\section{Recommendation}

Routine screening for domestic violence in infertility clinics should be mandatory to identify the victims, and provide them with appropriate health care and supportive services.

- Healthcare staff should consider husband attendance and good counseling about the drawback of all types of violence.

- The time has come to throw light on women exposure to violence, infertility itself threat the women mental and psychological health and violence add more stress and may complicate the treatment plan, it must be screened.

- It is necessary to provide a domestic violence programme within infertility care.

- Domestic violence victims may need primary care and special attention during her visits, and infertile women need to be educated by health care providers on how to prevent domestic violence.

- Increasing couples' knowledge about infertility and empowering women about their rights may decrease domestic violence.

\section{Further research:}

- Health care professionals should provide holistic care for infertile women to meet their physical, spiritual, psychological, and social needs.

\section{Reference:}

Abd El Moneim, A,. (2018). Traditional practices for treatment of infertility among rural women. Master thesis, Faculty of Nursing.Alexandria University. 3 (5):12-14
Ameh N., Kene TS., Onuh SO., etal, (2019). Burden of domestic violence amongst infertile women attending infertility clinics in Nigeria. Niger J Med; 16 (45): 375-377.

Andreeva $P$ (2018). "[Thyroid gland and fertility] [Article in Bulgarian]". Akush Ginekol (Sofiia); 53 (7): 18-23.

Ardabily, H,. Moghadam, Z,. Salsali M, Ramezanzadeh, F,. Nedjat, S,. (2018). Prevalence and risk factors for domestic violence against infertile

Budh, N,. (2018). Burden of Domestic Violence among Infertile Couples in Delhi: A Hospital Based Study.3 (7):12-15.

Elkhateeb, R,. (2018). Domestic violence against infertile women. 8 (1): 12-15.

(EDHS) (2018). Spousal violence: Available at https:// dhsprogram .com/pubs/pdf/ OF29 /OF29.pdf. Retrieved on 30, March, 2018.

Ghaly, A., Essa, R., \& Yassin, S,. (2019). Intimate partner violence against infertile women. 8 (4):10-25.

Hasan, E,. Ardabily Zahra, B,. Moghadam Mahvash Salsali Fatemeh Ramezanzadeh Saharnaz Nedjat,. (2017). Prevalence and risk factors for domestic violence against infertile women in an Iranian setting. First published: 18 October 2017 https://doi.org/10.1016/j.ijgo.2010.07.0

Keeling M., (2015): Violence against women: current theory and practice in domestic abuse, sexual violence and exploitation. In Kano, Northwest Nigeria. Int J Gynaecol Obstet. 3 (5): 21-25.

Li L,. Zhang, Y,. Zeng, D,. Li, F,. Cui, D,. (2018). Depression in Chinese men undergoing different assisted reproductive technique treatment:

Malgorzata Nagórska ,. Anna Bartosiewicz., Bogdan Obrzut ,and Mohamadian S., 
(2019). Prevalence and risk factors of domestic violence against Iranian women: A crosssectional study. In Northeastern region of Iran. Glob J Health Sci. 3 (7): 112-115.

Mohamadian S., (2016): Prevalence and risk factors of domestic violence against Iranian women: A cross-sectional study. In Northeastern region of Iran. Glob J Health Sci. 3 (7): 112-115.

Otwori, C. (2017). Causes and types of infertility amongst couples managed at Kenyatta national hospital. Published Master Thesis, Nairobi Prevalence and risk factors. J Assist Reprod Genet. 7 (30): 1161-7.

Potura,. Onat, G \& Merih, M,. (2019). An evaluation of the relationship between violence exposure status and personality characteristics among infertile women, Health Care for Women International.13 (8): 22-25.

Rahebi, SM,. Rahnavardi, M., RezaieChamani, S,. Nazari, M,.Sabetghadam, S,. (2019). Relationship between domestic violence and infertility. East Mediterr Health J. 25(8):https://doi.org/10.26719/emhj.19.001.

Rahnavardi M, Shayan A, Rezaie Chamani S, Heydarifard S, Rahebi M,. (2019). The Impact of Infertility on Sexual Violence in Women Referring to AL-Zahra Infertility Center in Rasht. Journal of Health and are.;21(1):44-52. Republic of Iran. 28 (11): 152-155.

Sami, N\& Ali, T,. (2016). Domestic violence against infertile women in Karachi, Pakistan. Asian Review of Social Sciences. 1(1):15-20.

Sheikhan, Z,. Ozgoli, G,. Azar, M,. Alavimajd, H,. (2019). Domestic violence in Iranian infertile women. Medical Journal of the Islamic

Taebi, M, . Dehaghi, A,. Nilforoushan, P,. (2016). Association between infertility factors and non-physical partner abuse in infertile couples.

Tahiri, F., Kalaja, D., Bimbashi, E. ( 2015). The lived experience of female infertility the case of Muslim rural women leaving in Albania. Univ Med Sci. 18(1): 10-17.

Xiaoli S, Mei L, Junjun B, Shu D, Zhaolian W, Jin W. (2016). Assessing the quality of life of infertile Chinese women: a cross-sectional study. Taiwan J Obstet Gynecol. 2016;55(2):244-50 


\section{تقييم العنف المنزلي بين النساء العقيمات المترددات علي مستثفي بنها الجامعي} مها غازي علي ديابـ ساميه عبد الدكيم حسانين عبود ـ سميه عوده عبد المنعم ـعلاعبدالوهاب عفيفي

يعد العنف القائم على السيدات مشكلة صحية عامة. يحدث العنف في جميع البلدان بغض النظر عن المجموعة

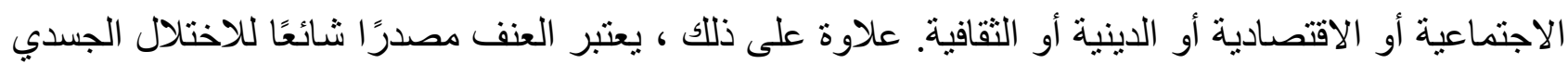

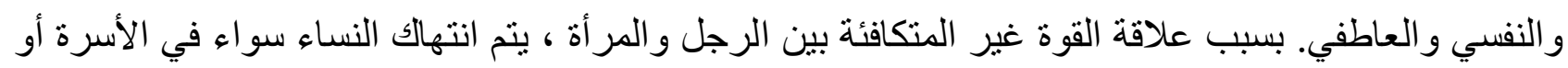

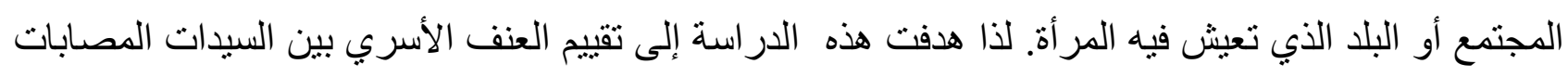

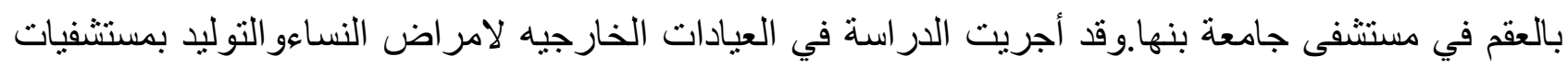

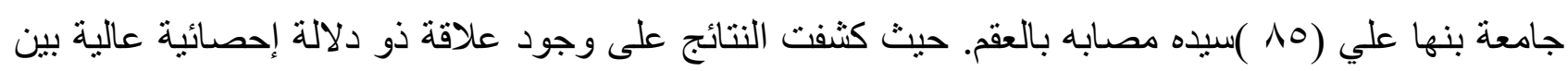
العنف الجسدي و العنف الجنسي و (السكن ونوع الاسرة) بالاضافه الي وجود علاقه ذات دلاله احصائيه عاليه بين العنف النفسي ومستوي التعليم لا توجدعلاقه ذات دلاله احصائيه بين العنف الجسدي و النفسي وتاريخ

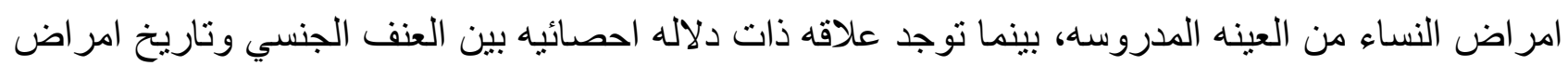

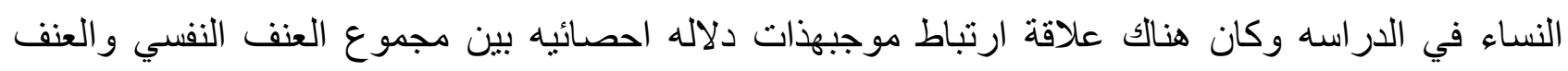

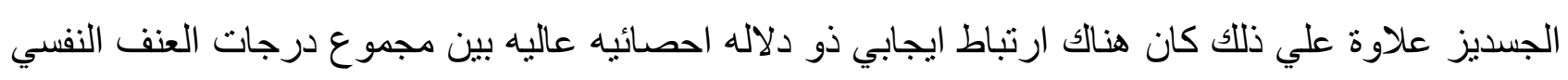

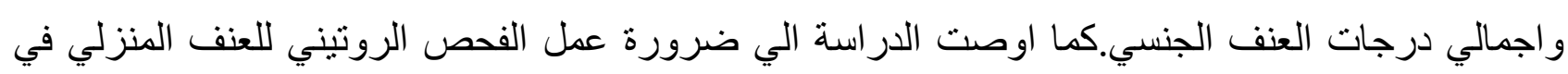
عبادات العقم إلز اميًا لتحديد الضحايا ، وتزويدهم بالر عاية الصحية و الخدمات الداعمة الدناسبة. 